\title{
PREPARATION OF ORAL CURCUMIN DELIVERY FROM 3D-NANO-CELLULOSE NETWORKS MATERIAL PRODUCED BY ACETOBACTER XYLINUM USING OPTIMIZATION TECHNIQUE
}

\author{
THANH XUAN NGUYEN*, HUONG LAN THI PHAM, THUONG THI NGO, PHONG XUAN ONG
}

Institute of Scientific Research and Applications, Hanoi Pedagogical University 2; Xuan Hoa, Phuc Yen, Vinh Phuc 280000, Vietnam Email: nguyenxuanthanh@hpu2.edu.vn

Received: 15 Dec 2019, Revised and Accepted: 11 Jan 2020

\begin{abstract}
Objective: To prepare oral curcumin delivery and optimize curcumin loading of 3D-nano-cellulose networks material (3DCM) by looking into the impact of process variables on the response utilizing response surface methodology (RSM) and Box-Behnken design.

Methods: Optimization of curcumin loading of 3DCM was conducted using RSM and Box-Behnken model. Impact of four independent variables, including, the concentration of curcumin $\left(\mathrm{X}_{1}\right)$, temperature $\left(\mathrm{X}_{2}\right)$, shaking speed $\left(\mathrm{X}_{3}\right)$, and time of loading $\left(\mathrm{X}_{4}\right)$, was studied on one dependent response, that is, an amount of loaded curcumin (Y). Characterization of optimized 3DCM including curcumin was examined by Scanning Electron Microscopy (SEM) and Fourier Transform Infrared (FTIR) analysis .
\end{abstract}

Results: $\mathrm{R}^{2}$ value for $\mathrm{Y}$ was approximately 0.94 . $\mathrm{X}_{1}$ possessed the biggest positive impact compared to $\mathrm{X}_{2}, \mathrm{X}_{3}$ and $\mathrm{X}_{4}$. Optimized conditions for curcumin loading of $3 D C M$ were $X_{1}$ at $3 \mathrm{mg} / \mathrm{ml}, X_{2}$ at $40{ }^{\circ} \mathrm{C}, X_{3}$ at $120 \mathrm{rpm}$ and $X_{4}$ at $120 \mathrm{~min}$. SEM photograph of 3DCM surfaces were found including fibers creating a 3D network structure. FTIR spectra studies depicted that there was no interaction between curcumin and 3DCM.

Conclusion: The data obtained in this study thus suggest that curcumin loaded 3DCM was successfully fabricated to give a potential oral delivery system of curcumin.

Keywords: Acetobacter xylinum, Characterization, Curcumin, Loading, Optimization, 3D-nano-cellulose networks material (3DCM)

(C) 2020 The Authors. Published by Innovare Academic Sciences Pvt Ltd. This is an open access article under the CC BY license (http://creativecommons.org/licenses/by/4.0/) DOI: http://dx.doi.org/10.22159/ijap.2020v12i2.36627. Journal homepage: https://innovareacademics.in/journals/index.php/ijap

\section{INTRODUCTION}

The 3D-nano-cellulose networks material (3DCM) has the structure of super-thin nano fibers, great tensile, high capacity of keeping water, mechanical strength, simplicity of producing into a desirable form,... and the 3DCM is proven to have the potential of being a drug delivery system by its superior properties $[1,2]$. The use of 3DCM of coconut jelly (made from coconut juice after the fermentation of bacteria Acetobacter xylinum) in the coating for Paracetamol by spraying technique was reported [3]. Results have indicated that the 3DCM membranes are able to increase releasing time of the drug and improve the efficiency of drug users. 3DCM membrane from the fermentation of Gluconacetobacter xylinum in the standard medium (Hestrin-Schramm) for transporting and releasing berberine in vitro was tested [4]. The experiment has controlled the drug releasing of the 3DCM in artificial models, including stomach and intestine. The gained information has shown that berberine released with low rate in acidic condition, normal in alkaline condition and high releasing rate in neutral $\mathrm{pH}$ condition. It was demonstrated that 3DCM is a potential choice to gelatin capsules with both fast and slow release properties of the drug depending upon the constitutions of the enclosed materials [5]. 3DCM was produced by Gluconacetobacter xylinus as substances for famotidine and tizanidine delivery of oral route [6]. Results of drug loading and drug release studies in vitro have shown that 3DCM was a promising material for applications in drug delivery through the oral route. Curcumin ([1,7-bis-(4-hydroxy-3-methoxyphenyl)-1,6heptadiene-3,5-dione] (diferuloyl methane)), a phenolic compound, is present in many kinds of medicinal plants, especially in Curcuma longa (turmeric). Curcumin possesses a wide spectrum of biological and pharmacological activities, such as anti-inflammatory, anticancer, and other pharmacological activities $[7,8]$. However, curcumin has not yet been approved as a therapeutic agent due to its limited aqueous solubility and degradation at alkaline $\mathrm{pH}$ hinder its bioavailability [9]. One of the attempts to improve its bioavailability is utilizing proper delivery vehicles to maximize the absorption and stability of curcumin in the upper gastrointestinal tract. Curcumin loaded on cassava starch nanoparticles demonstrated improved cellular absorption with nontoxic to normal cells [10]. It is demonstrated that the use of olive oil nanoemulsions as a delivery vehicle for curcumin with excellent release characteristics and the ability to protect curcumin in an aqueous environment [11]. Moreover, solid lipid nanoparticles of curcuminoids were formulated and characterized in order to improve poor oral bioavailability of curcumin [12]. In vivo pharmacokinetics study in rats was conducted to demonstrate improved oral bioavailability. This research aims to prepare oral curcumin delivery and optimize curcumin loading of 3D-nano-cellulose networks material (3DCM) for designing a potential delivery system of curcumin.

\section{MATERIALS AND METHODS}

\section{Materials}

The bacterial strain of Acetobacter xylinum producing cellulose was isolated and cultured in the clean room of microorganism, Institute of Scientific Research and Applications (ISA)-Hanoi Pedagogical University 2 (HPU2), Vietnam.

Curcumin (95\% purity) was purchased from Apollo (India), whereas yeast extracts were purchased from Sigma-Aldrich (USA). Peptone was purchased from ECHA (European Union) and other standard chemicals used in the analysis were purchased from China.

\section{Methods}

Fabrication of 3D-nano-cellulose networks material (3DCM)

3DCM was produced by Acetobacter xylinum using the method of static culture in Hestrin-Schramm (HS) liquid medium $[2,13]$ which was composed of D-glucose $(2 \%)$, peptone $(0.5 \%)$, yeast extract $(0.5 \%)$, sodium dihydrogen phosphate $(0.27 \%)$, and citric acid $(0.115 \%)$ in distilled water $(\mathrm{pH}=6)$, and sterilized at $121^{\circ} \mathrm{C}$ for 20 min. The pre-culture was inoculated into a previously sterilized 24well plate containing HS medium and incubated in a static incubator (Binder, Germany) at $28^{\circ} \mathrm{C}$ for $15 \mathrm{~d}$. 3DCM was rinsed thoroughly with distilled water and treated with $0.3 \mathrm{M} \mathrm{NaOH}$ solution in an autoclave (Hirayama, Japan) at $121^{\circ} \mathrm{C}$ for $20 \mathrm{~min}$ to eliminate any remnants of bacterial colonies. The 3DCM was again thoroughly rinsed with distilled water till reaching neutral $\mathrm{pH}$ and stored at $4{ }^{\circ} \mathrm{C}$ for further use $[5,6]$. 


\section{Experimental design}

Response surface methodology (RSM) is one of the popular methods in the development and optimization of drug delivery systems. Based on the principles of design of experiments, the methodology involves the use of various types of experimental designs, generation of polynomial mathematical relationships, and mapping of the response over the experimental domain to select the optimum formulation. Box-Behnken design is one type of RSM designs available for statistical optimization of the formulations [14]. A BoxBehnken experimental design was employed to statistically optimize the curcumin loading parameters of 3DCM for maximum curcumin entrapment. The Box-Behnken design was specifically selected since it requires fewer treatment combinations than other designs in cases involving three or four factors. The Box-Behnken design is also rotable and contains statistical missing corners, which may be useful when the experimenter is trying to avoid combined factor extremes. This property prevents a potential loss of data in those cases. Generation and evaluation of the statistical experimental design were performed with the JMP10 software. A design matrix comprising of 27 experimental runs was constructed. The independent and dependent variables are listed in table 1 . The polynomial equation generated by the experimental design is as follows: $Y=b_{0}+b_{1} X_{1}+b_{2} X_{2}+b_{3} X_{3}+b_{4} X_{4}+b_{5} X_{1} X_{2}+b_{6} X_{1} X_{3}+$ $b_{7} X_{1} X_{4}+b_{8} X_{2} X_{3}+b_{9} X_{2} X_{4}+b_{10} X_{3} X_{4}+b_{11} X_{1}^{2}+b_{12} X_{2}^{2}+b_{13} X_{3}^{2}+b_{14} X_{4}^{2}$ (1) [14].

Where, $Y$ is the measured response of the dependent variables; $b_{0}$ is the intercept; $b_{1}$ to $b_{14}$ are the regression coefficients computed from the observed experimental values of $Y . X_{1}, X_{2}, X_{3}$, and $X_{4}$ is the coded value of the independent variables that were selected from the preliminary experiments. $X_{a} X_{b}(a, b=1,2,3,4)$ and $X_{i}^{2}(i=1,2,3,4)$ represented the interaction and quadratic terms, respectively.

Table 1: The levels of independent and dependent variables in Box-Behnken design

\begin{tabular}{lll}
\hline Factor & \multicolumn{2}{l}{ Levels used, actual (coded) } \\
\cline { 2 - 3 } & Low (-1) & Medium (0) \\
\hline$X_{1}=$ Concentration $(\mathrm{mg} / \mathrm{ml})$ & 1 & 2 \\
$X_{2}=$ Temperature $\left({ }^{\circ} \mathrm{C}\right)$ & 40 & 50 \\
$X_{3}=$ Shaking speed $(\mathrm{rpm})$ & 120 & 160 \\
$X_{4}=$ Time (min) & 60 & 90 \\
$Y_{i}=$ Amount of loaded curcumin $(\mathrm{mg})$ & Maximize & 200 \\
\end{tabular}

\section{Determination of curcumin loaded into 3DCM}

The 3DCM produced by Acetobacter xylinum in a Hestrin-Schramm (HS) liquid medium with the diameter $1.5 \mathrm{~cm}$ and thickness $1 \mathrm{~cm}$ was added a curcumin solution by using absorption method [15]. After a period of loading, the spectrophotometry (Spectrograph UVVis 2450, Shimadru, Japan) was performed to determine an excessive amount of curcumin in the solution $[2,6,15]$ at the time of sampling. The amount of curcumin loaded into 3DCM is calculated according to formula $2: \mathrm{m}_{\mathrm{cl}}=\mathrm{m}_{1}-\mathrm{m}_{2}(\mathrm{mg})(2)[2,16]$. Where: $\mathrm{m}_{\mathrm{cl}}$ is the amount of curcumin that is loaded into the $3 \mathrm{DCM} ; \mathrm{m}_{1}$ is the initial amount of curcumin in solution; $\mathrm{m}_{2}$ is the excessive amount of curcumin existing in solution after a certain period of time 3DCM loading curcumin.

\section{Scanning electron microscopy (SEM)}

The surface topography and morphology of the 3DCM were visualized by a field-emission scanning electron microscopy (FESEM, $\mathrm{S}-4800$, Hitachi, Japan). The samples heat at $40{ }^{\circ} \mathrm{C}$ in $20 \mathrm{~min}$, cover, then a thin platinum layer and put into the sample chamber [17].

\section{Fourier transform infrared (FTIR) analysis}

FTIR analysis was performed to study the chemical interaction between curcumin and 3DCM using FTIR Affinity-1S (Shimadru, Japan). Spectra for all samples is directly measured by Reflectometry in $20^{\circ} \mathrm{C}$, moisture $40-43 \%$. The samples were scanned in the IR range from 400 to $4000 \mathrm{~cm}^{-1}$ [17]. Interaction between the components, if any, was indicated by either producing additional peaks or absence of characteristic peak corresponding to curcumin and 3DCM.

\section{Data analysis and statistics}

Data are reported as mean \pm SD (Standard deviation) and the difference between the groups were tested using two-way ANOVA, using Microsoft Excel 2010 and JMP10 software. The differences were statistically significant when $\mathrm{P}<0.05$.

\section{RESULTS}

\section{Optimization of curcumin loading of 3DCM}

From the preliminary studies, it was observed that the concentration of curcumin, temperature, shaking speed, and time of loading contributed much towards the change in amount of curcumin loaded into 3DCM using the absorption method. Therefore, Box-Behnken design was applied in this study to optimize the curcumin loading of 3DCM. The experimental matrix from the randomized runs for the independent variables and response observed is shown in table 2 .
The response was simultaneously fitted to regression models by using the JMP10 software. Actual versus predicted profile, analysis of variance and lack of fit for the response amount of loaded curcumin into 3DCM has been given in fig. 1. By comparing statistical parameters, such as P-value and squared correlation coefficient (RSq) it was found that regression model was fitting in the mathematical model for the response. P-value for the response amount of loaded curcumin into 3DCM (Y) was less than 0.0001 . $\mathrm{P}<0.05$ indicated that the model is statistically significant. The RSq value defines the total variation shown by the model. The RSq value should be close to 1 for a good model fit. The RSq value of the response $\mathrm{Y}$ was approximately 0.94 .

The polynomial equation was used to draw the conclusions after considering the magnitude of coefficient and the mathematical sign it carried. The mathematical relationship in the form of factor's coefficients, its corresponding P-values for the measured response and correlation coefficient are shown in table 3. Coefficients with Pvalue less than 0.05 had a significant effect on the prediction efficacy of the model of the measured response. The high values of the correlation coefficient for the dependent variable indicated a good fit. The amount of loaded curcumin into 3DCM (dependent variable, $\mathrm{Y})$ obtained at various levels of the four independent variables $\left(\mathrm{X}_{1}\right.$, $\mathrm{X}_{2}, \mathrm{X}_{3}$ and $\mathrm{X}_{4}$ ) was subjected to multiple regressions to yield a second-order polynomial equation (full model).

$\mathrm{Y}=9.49+4.26 \mathrm{X}_{1}-0.37 \mathrm{X}_{2}-0.08 \mathrm{X}_{3}+0.60 \mathrm{X}_{4}-0.08 \mathrm{X}_{1} \mathrm{X}_{2}-0.59 \mathrm{X}_{1} \mathrm{X}_{3}+1.26 \mathrm{X}_{1} \mathrm{X}_{4}$ $-0.09 \mathrm{X}_{2} \mathrm{X}_{3}-0.59 \mathrm{X}_{2} \mathrm{X}_{4}-0.08 \mathrm{X}_{3} \mathrm{X}_{4}-1.85 \mathrm{X}_{1}{ }^{2}-0.35 \mathrm{X}_{2}^{2}+0.03 \mathrm{X}_{3}{ }^{2}-0.67 \mathrm{X}_{4}^{2}$ (3)

The amount of loaded curcumin into 3DCM values measured for the different batches showed wide variation (i.e., Values ranged from a minimum of 1.14 to a maximum of 14.55 ). The results clearly indicated that the amount of loaded curcumin in 3DCM value was strongly affected by the variables selected for the study. This was also reflected by the wide range of values for the coefficients of the terms of equation 3 . The main effects of $X_{1}, X_{2}, X_{3}$ and $X_{4}$ represented the average result of changing one variable at a time from its lowest level to its high level. The interaction terms $\left(\mathrm{X}_{1} \mathrm{X}_{2}, \mathrm{X}_{1} \mathrm{X}_{3}, \mathrm{X}_{1} \mathrm{X}_{4}, \mathrm{X}_{2} \mathrm{X}_{3}\right.$, $\mathrm{X}_{2} \mathrm{X}_{4}, \mathrm{X}_{3} \mathrm{X}_{4}, \mathrm{X}_{1}{ }^{2}, \mathrm{X}_{2}{ }^{2}, \mathrm{X}_{3}{ }^{2}$ and $\mathrm{X}_{4}{ }^{2}$ ) showed how the amount of loaded curcumin into 3DCM changed when two variables were simultaneously changed. Concerning the amount of loaded curcumin into 3DCM, the results of multiple linear regression analysis showed that both the coefficients $b_{1}$ and $b_{4}$ had a positive sign while $b_{2}$ and $b_{3}$ had a negative sign $\left(R^{2}=0.94\right)$.

Equation 3 and from the parameter estimates shown in table 3 revealed $X_{1}$ had the largest positive effect compared to $X_{2}, X_{3}$ and $X_{4}$. 
Table 2: Experiment based on box-behnken design and the observed amount of loaded curcumin into 3DCM results

\begin{tabular}{|c|c|c|c|c|c|c|}
\hline S. No. & Pattern & Concentration (mg/ml) & Temperature $\left({ }^{\circ} \mathrm{C}\right)$ & Shaking speed (rpm) & Time (min) & Amount of loaded curcumin (mg) \\
\hline 1 & $+0+0$ & 3 & 50 & 200 & 90 & $10.51 \pm 1.65$ \\
\hline 2 & $+00-$ & 3 & 50 & 160 & 60 & $9.76 \pm 1.48$ \\
\hline 3 & $0--0$ & 2 & 40 & 120 & 90 & $9.46 \pm 1.41$ \\
\hline 4 & 0000 & 2 & 50 & 160 & 90 & $9.45 \pm 1.31$ \\
\hline 5 & +-00 & 3 & 40 & 160 & 90 & $10.85 \pm 1.37$ \\
\hline 6 & $00--$ & 2 & 50 & 120 & 60 & $8.24 \pm 0.91$ \\
\hline 7 & ++00 & 3 & 60 & 160 & 90 & $10.49 \pm 1.50$ \\
\hline 8 & --00 & 1 & 40 & 160 & 90 & $4.13 \pm 0.17$ \\
\hline 9 & $00+-$ & 2 & 50 & 200 & 60 & $9.22 \pm 1.06$ \\
\hline 10 & $0+-0$ & 2 & 60 & 120 & 90 & $8.62 \pm 1.36$ \\
\hline 11 & $0++0$ & 2 & 60 & 200 & 90 & $8.18 \pm 1.18$ \\
\hline 12 & $+0-0$ & 3 & 50 & 120 & 90 & $12.72 \pm 1.72$ \\
\hline 13 & $-00+$ & 1 & 50 & 160 & 120 & $1.14 \pm 0.13$ \\
\hline 14 & $0-+0$ & 2 & 40 & 200 & 90 & $9.36 \pm 1.83$ \\
\hline 15 & 0000 & 2 & 50 & 160 & 90 & $9.53 \pm 1.45$ \\
\hline 16 & -+00 & 1 & 60 & 160 & 90 & $4.08 \pm 0.14$ \\
\hline 17 & $0-0-$ & 2 & 40 & 160 & 60 & $8.13 \pm 1.01$ \\
\hline 18 & $-00-$ & 1 & 50 & 160 & 60 & $1.37 \pm 0.15$ \\
\hline 19 & $+00+$ & 3 & 50 & 160 & 120 & $14.55 \pm 1.79$ \\
\hline 20 & $00++$ & 2 & 50 & 200 & 120 & $9.49 \pm 1.39$ \\
\hline 21 & $-0-0$ & 1 & 50 & 120 & 90 & $4.04 \pm 0.19$ \\
\hline 22 & $0-0+$ & 2 & 40 & 160 & 120 & $10.20 \pm 1.43$ \\
\hline 23 & $00-+$ & 2 & 50 & 120 & 120 & $8.82 \pm 2.41$ \\
\hline 24 & $0+0+$ & 2 & 60 & 160 & 120 & $8.03 \pm 1.77$ \\
\hline 25 & $0+0-$ & 2 & 60 & 160 & 60 & $8.31 \pm 1.96$ \\
\hline 26 & $-0+0$ & 1 & 50 & 200 & 90 & $4.18 \pm 1.02$ \\
\hline 27 & 0000 & 2 & 50 & 160 & 90 & $9.50 \pm 2.48$ \\
\hline
\end{tabular}

Note: All data representing an average of 3 trials $(n=3)$, given as mean $\pm S D$

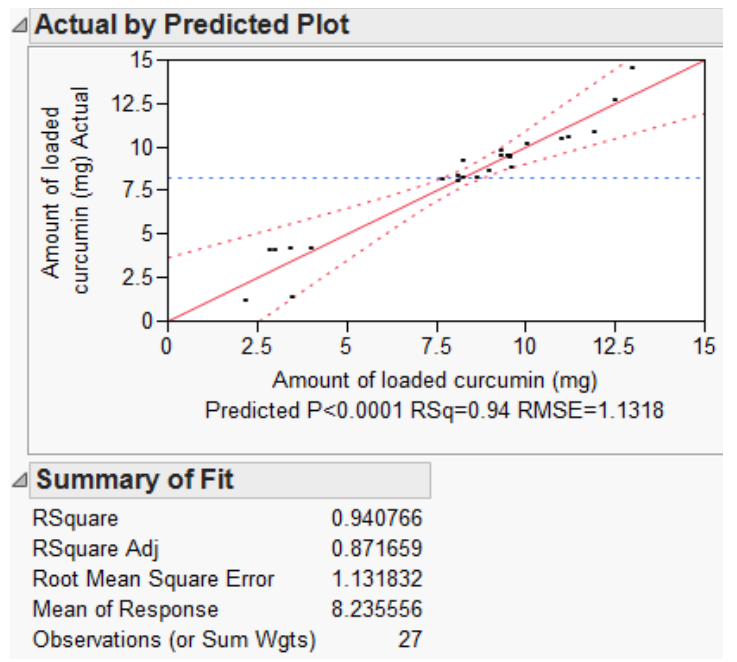

\begin{tabular}{lrrrr}
\hline \multicolumn{5}{|c|}{ Analysis of Variance } \\
$\begin{array}{lrrrr}\text { Sum of } \\
\text { Source } & \text { DF } & \text { Squares } & \text { Mean Square } & \text { F Ratio } \\
\text { Model } & 14 & 244.14813 & 17.4392 & 13.6132 \\
\text { Error } & 12 & 15.37253 & 1.2810 & \text { Prob }>\text { F } \\
\text { C. Total } & 26 & 259.52067 & & <.0001^{*}\end{array}$
\end{tabular}

\begin{tabular}{lrrrr|}
\hline Lack Of Fit & \multicolumn{4}{c|}{ Sum of } \\
Source & DF & Squares & Mean Square & F Ratio \\
Lack Of Fit & 10 & 15.369267 & 1.53693 & 940.9755 \\
Pure Error & 2 & 0.003267 & 0.00163 & Prob > F \\
Total Error & 12 & 15.372533 & & $0.0011^{\star}$ \\
& & & \\
& & & Max RSq \\
& & & 1.0000
\end{tabular}

Fig. 1: Actual versus predicted profile, analysis of variance and lack of fit for the response amount of loaded curcumin into 3DCM

Table 3: The parameter estimates for the response amount of loaded curcumin into 3DCM

\begin{tabular}{|c|c|c|c|c|}
\hline Term & Estimate & Std error & t Ratio & Prob $>|\mathbf{t}|$ \\
\hline Intercept & 9.4933 & 0.6534 & 14.53 & $<0.0001^{*}$ \\
\hline Concentration $(\mathrm{mg} / \mathrm{ml})(1,3)$ & 4.1616 & 0.3267 & 12.74 & $<0.0001^{*}$ \\
\hline Temperature $\left({ }^{\circ} \mathrm{C}\right)(40,60)$ & -0.3683 & 0.3267 & -1.13 & 0.2816 \\
\hline Shaking speed (rpm) $(120,200)$ & -0.08 & 0.3267 & -0.24 & 0.8107 \\
\hline Time $(\min )(60,120)$ & 0.6 & 0.3267 & 1.84 & 0.0912 \\
\hline Concentration $(\mathrm{mg} / \mathrm{ml}) \times$ Temperature $\left({ }^{\circ} \mathrm{C}\right)$ & -0.0775 & 0.5659 & -0.14 & 0.8933 \\
\hline Concentration $(\mathrm{mg} / \mathrm{ml}) \times$ Shaking speed $(\mathrm{rpm})$ & -0.5875 & 0.5659 & -1.04 & 0.3197 \\
\hline Temperature $\left({ }^{\circ} \mathrm{C}\right) \times$ Shaking speed $(\mathrm{rpm})$ & -0.085 & 0.5659 & -0.15 & 0.8831 \\
\hline Concentration $(\mathrm{mg} / \mathrm{ml}) \times$ Time $(\mathrm{min})$ & 1.255 & 0.5659 & 2.22 & 0.0466 \\
\hline Temperature $\left({ }^{\circ} \mathrm{C}\right) \times$ Time $(\mathrm{min})$ & -0.5875 & 0.5659 & -1.04 & 0.3197 \\
\hline Shaking speed (rpm) x Time (min) & -0.0775 & 0.5659 & -0.14 & 0.8933 \\
\hline Concentration $(\mathrm{mg} / \mathrm{ml}) \times$ Concentration $(\mathrm{mg} / \mathrm{ml})$ & -1.8475 & 0.4900 & -3.77 & $0.0027^{*}$ \\
\hline Temperature $\left({ }^{\circ} \mathrm{C}\right) \times$ Temperature $\left({ }^{\circ} \mathrm{C}\right)$ & -0.345 & 0.4900 & -0.70 & 0.4949 \\
\hline Shaking speed (rpm) x Shaking speed (rpm) & 0.03 & 0.4900 & 0.06 & 0.9522 \\
\hline Time (min) x Time (min) & -0.6675 & 0.4900 & -1.36 & 0.1982 \\
\hline
\end{tabular}


The results in table 3 showed that the interaction terms, only coefficients $\mathrm{b} 7$ and b11 were significant at $\mathrm{P}<0.05$. It could be concluded that the interaction terms b5, b6, b8, b9, b10, b12, b13 and b14 did not contribute significantly to the prediction of $Y$, and the low coefficients of these terms in equation 3 indicated that these terms contributed the least to the prediction of Y. It was deduced that concentration of curcumin $\left(\mathrm{X}_{1}\right)$ and its interaction with time of loading $\left(\mathrm{X}_{4}\right)$ contributed to the regression model more than others.
In order to determine the optimal value of the four experimental factors for a maximum amount of loaded curcumin into 3DCM, the expected point will be maximized using the prediction curve through prediction tools in JMP10 software (Prediction Profiler). The results in fig. 2 showed that the maximum amount of loaded curcumin into 3DCM can reach $14.37 \mathrm{mg}$ when reacting to concentration of curcumin at $3 \mathrm{mg} / \mathrm{ml}$, the temperature at $40{ }^{\circ} \mathrm{C}$, shaking speed at $120 \mathrm{rpm}$, and time of loading at $120 \mathrm{~min}$.

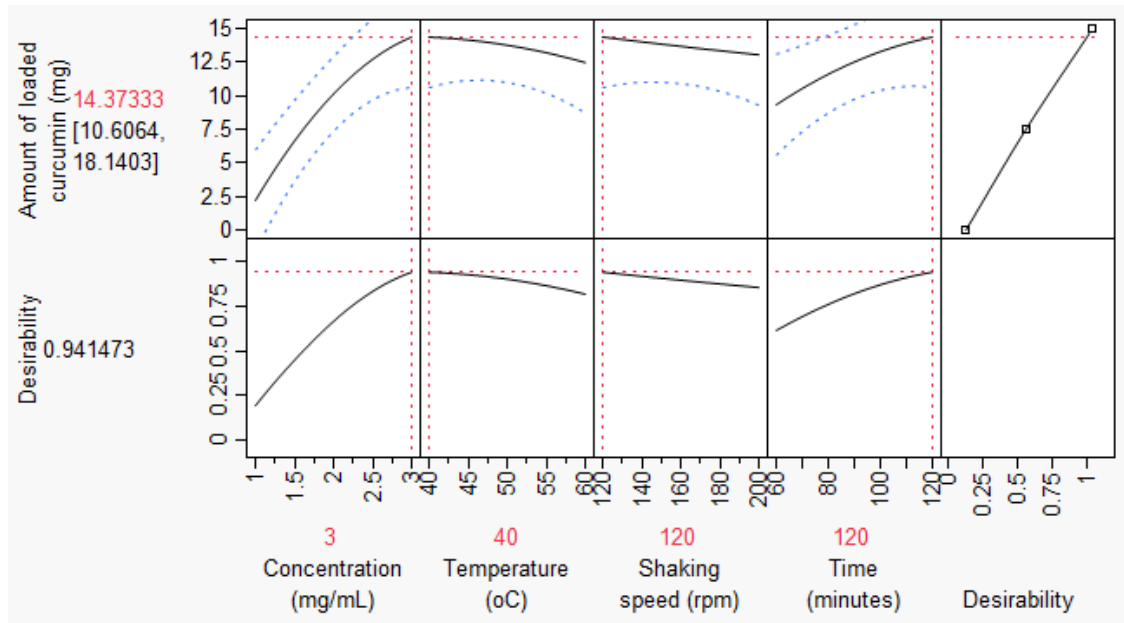

Fig. 2: Prediction profiler response amount of loaded curcumin into 3DCM

After determining the optimum conditions for curcumin loading of 3DCM, in order to test the compatibility of the model for the experiment, the amount of loaded curcumin into 3DCM was taken 4 times at the predicted conditions shown in table 4.

Table 4: Comparison between the experimental and predicted values for the most probable optimal conditions

\begin{tabular}{|c|c|c|}
\hline \multirow[t]{2}{*}{ Dependent variable } & \multicolumn{2}{|c|}{ Optimized conditions $\left(3 \mathrm{mg} / \mathrm{ml}, 40^{\circ} \mathrm{C}, 120 \mathrm{rpm}, 120 \mathrm{~min}\right)$} \\
\hline & Experimental & Predicted \\
\hline Amount of loaded curcumin into 3DCM & $14.47 \pm 0.87 \mathrm{mg}$ & $14.37 \mathrm{mg}$ \\
\hline
\end{tabular}

Note: All data representing an average of 4 trials $(n=4)$, given as mean $\pm S D$

Comparison between the experimental and predicted values for the most probable optimal conditions is reported in table 4 .

The experimental test showed that the results on the amount of loaded curcumin into 3DCM at the optimized conditions $(14.47 \pm 0.87)$ with an insignificant difference from the predicted

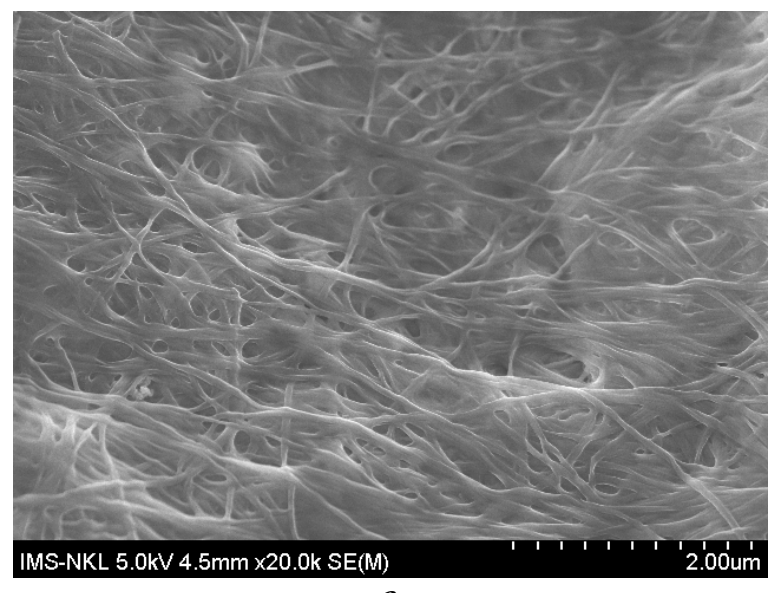

a result (14.37) of the model $(\mathrm{P}>0.05)$, and amount of loaded curcumin were well within the predetermined specifications. From this, it can be concluded that as predicted value agreed well with the experimental values, demonstrating the feasibility of the optimized conditions in the development of a potential curcumin delivery system from curcumin loaded 3DCM.

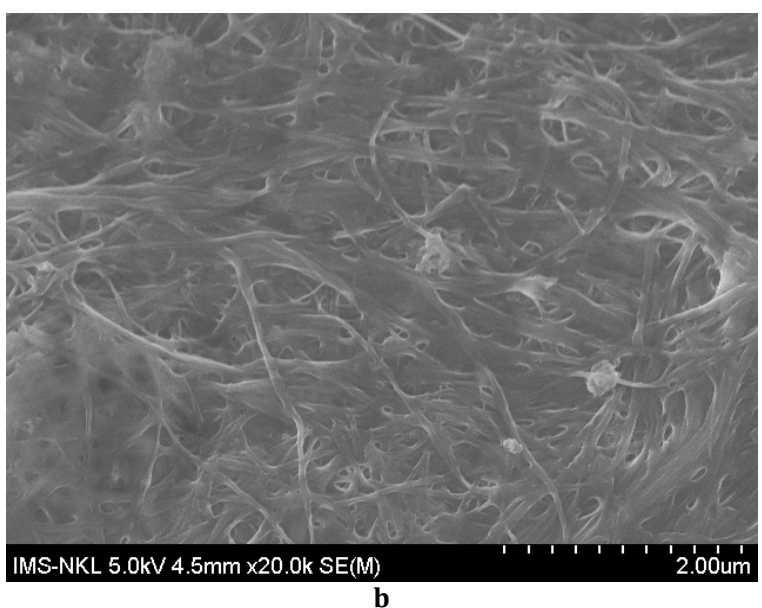

Fig. 3: Scanning electron microscopy images of curcumin unloaded 3DCM (a) and optimized curcumin loaded 3DCM (b) 


\section{Characterization of optimized curcumin loaded 3DCM}

The morphological characteristics of the curcumin loaded 3DCM were observed using FESEM. As shown in fig. 3a and 3b, the prepared curcumin unloaded 3DCM and curcumin loaded 3DCM were found to be composed of entangled fibers, forming an interconnected web-like structure. As the results, 3DCMs have the homogeneous fiber structure networks without significant changes in structure before and after loading curcumin.

FTIR analysis of pure curcumin, pure 3DCM and optimized curcumin loaded 3DCM was performed to investigate the interaction between curcumin and 3DCM. Fig. 4 shows FTIR spectra of curcumin, 3DCM and optimized curcumin loaded 3DCM.

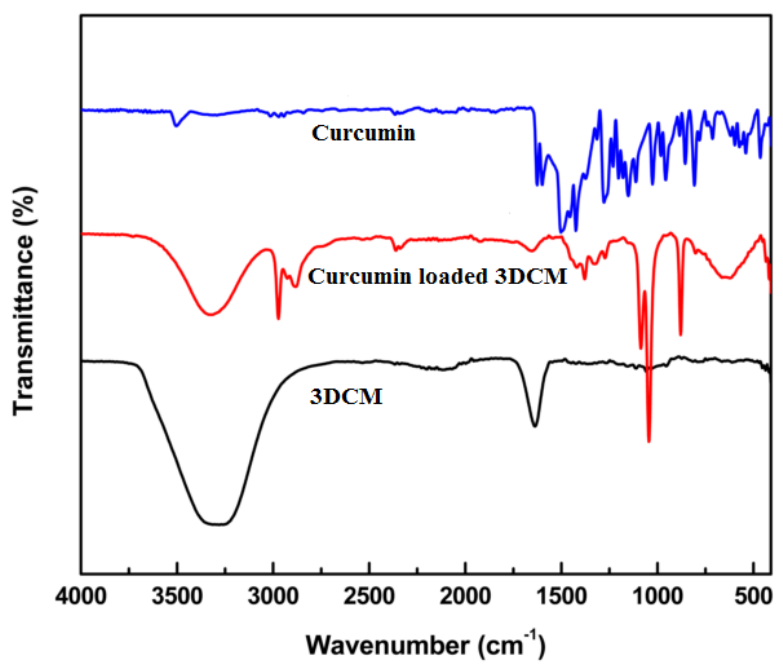

Fig. 4: FTIR spectra of pure curcumin, pure 3DCM and optimized curcumin loaded 3DCM

The FTIR spectra of 3DCM displayed the typical features of cellulosic substrates with intense bands around $3300,2880,1100$ and $700 \mathrm{~cm}$ 1 , associated with the vibrations of the $-\mathrm{OH}, \mathrm{C}-\mathrm{H}, \mathrm{C}-\mathrm{O}-\mathrm{C}$ and $-\mathrm{CH}_{2}-$ groups, respectively $[4,17]$. In the optimized curcumin loaded 3DCM, no additional peaks attributable to the formation of a complex appeared, but variations in the relative intensities of the characteristic peaks for 3DCM, and the curcumin can be observed.

\section{DISCUSSION}

The results of optimized curcumin loaded 3DCM are consistent with other studies about the structure of 3DCM including nano-sized cellulose fibers that make up the three-dimensional structure network $[4-6,17]$. Furthermore, in another study, the SEM micrographs indicated that the fibers of freeze-dried 3DCM were interwoven more loosely with fiber-covered pores present on the surface, in contrast, the structure of oven-dried 3DCM was more compact with no visible pores on the surface [5]. The changes in the pore sizes of 3DCM analyzed by SEM showed that the porosity decreased after acid or alkali treatment, indicating fiber expansion, and neutral buffer had no effect on 3DCM fibers [4]. However, in this study, investigation of the 3DCM structure using FESEM showed that the cellulose fibers of 3DCM have a stable structure without structural change when loading curcumin under optimal condition. The FTIR spectrum of a physical mixture shows all characteristic peaks with minor shifts indicating an absence of interactions. Consequently, between the curcumin and 3DCM without the formation of covalent bonds, the optimized curcumin loaded 3DCM; therefore, only involved noncovalent bonding forces. The appearance of specific absorption peaks associated with functional groups of 3DCM and curcumin revealed the successful curcumin loading into 3DCM without any chemical alteration in the structure of the curcumin and 3DCM. The results are in agreement with the previous studies $[4,5,17]$.

\section{CONCLUSION}

Curcumin loaded 3DCM, a potential curcumin delivery system, was successfully fabricated by absorption method and optimization technique using RSM and Box-Behnken model. The study demonstrated that the results on the amount of loaded curcumin into 3DCM at the optimized conditions with an insignificant difference from the predicted result of the model, and amount of loaded curcumin were well within the predetermined specifications. Optimized conditions for curcumin loading of 3DCM were the concentration of curcumin at $3 \mathrm{mg} / \mathrm{ml}$, temperature at $40{ }^{\circ} \mathrm{C}$, shaking speed at $120 \mathrm{rpm}$ and time of loading at $120 \mathrm{~min}$. SEM imaging, the 3DCM surfaces were found to be composed of entangled fibers, forming an interconnected web-like structure. FTIR spectra studies depicted that there was no interaction between curcumin and 3DCM. The results indicate the potential for using 3DCM to design the oral curcumin delivery system.

\section{ACKNOWLEDGMENT}

This research has benefited from the financial support of Ministry of Education and Training (Code number: B2017-SP2-09). The authors are thankful to the members of Biomedical and Pharmaceutical Engineering Research Group at Institute of Scientific Research and Applications (ISA)-Hanoi Pedagogical University 2 (HPU2) and collaborative members help to do some of the work of this research.

\section{AUTHORS CONTRIBUTIONS}

The authors declare that this work was done by the authors named in this article and all liabilities pertaining to claims relating to the content of this article will be borne by them.

\section{CONFLICT OF INTRESTS}

The authors declare no conflicts of interest.

\section{REFERENCES}

1. Ullah H, Santo HA, Khan T. Applications of bacterial cellulose in food, cosmetics and drug delivery. Cellulose 2016;23:2291-314

2. Moniri M, Moghaddam AB, Azizi S, Rahim RA, Ariff AB, Saad $\mathrm{WZ}$, et al. Production and status of bacterial cellulose in biomedical engineering. Nanomaterials (Basel) 2017;7:1-26.

3. Amin MCIM, Abadi A, Ahmad N, Katas H, Jamal JA. Bacterial cellulose film coating as drug delivery system: physicochemical, thermal and drug release properties. Sains Malays 2012;41:561-8.

4. Huang L, Chen X, Nguyen TX, Tang H, Zhang L, Yang G. Nanocellulose 3D-networks as controlled-release drug carriers. J Mater Chem B 2013;1:2976-84.

5. Ullah H, Badshah M, Makila E, Salonen J, Shahbazi MA, Santos $\mathrm{HA}$, et al. Fabrication, characterization and evaluation of 
bacterial cellulose-based capsule shells for oral drug delivery. Cellulose 2007;24:1445-54.

6. Badshah M, Ullah H, Khan SA, Park JK, Khan T. Preparation characterization and in vitro evaluation of bacterial cellulose matrices for oral drug delivery. Cellulose 2017;24:5041-52.

7. Maheshwari RK, Singh AK, Gaddipati J, Srimal RC. Multiple biological activities of curcumin: a short review. Life Sci 2006;78:2081-7.

8. Samal HB, Das IJ, Patra CN, Sreenivas SA. Design and in vitro evaluation of curcumin dental films for the treatment of periodontitis. Asian J Pharm 2017;11:579-87.

9. Gupta SC, Patchva S, Aggarwal BB. Therapeutic roles of curcumin: lessons learned from clinical trials. AAPS J 2013;15:195-218.

10. Athira GK, Jyothi AN. Preparation and characterization of curcumin loaded cassava starch nanoparticles with improved cellular absorption. Int J Pharm Pharm Sci 2014;6:171-6.

11. Franklyne JS, Nadarajan AR, Ebenazer A, Tiwari N, Mukherjee A, Chandrasekaran N. Preparation and characterization of edible oil nanoemulsions for enhanced stability and oral delivery of curcumin. Int J Appl Pharm 2018;10:139-46.
12. Shelat P, Mandowara VK, Gupta DG, Patel S. Formulation of curcuminoid loaded solid lipid nanoparticles in order to improve oral bioavailability. Int J Pharm Pharm Sci 2015;7:278-82

13. Hestrin S, Schramm M. Synthesis of cellulose by Acetobacter xylinum, 2. Preparation of freeze-dried cells capable of polymerizing glucose to cellulose. Biochem J 1954;58:345-52.

14. Bhattacharya S. Statistical interpretation and optimization of valsartan floating tablets using Box-Behnken design. Int J Appl Pharm 2019;11:44-53.

15. Kuswandi B, Jayus, Larasati TS, Abdullah A, Heng LY. Real-time monitoring of shrimp spoilage using on-package sticker sensor based on natural dye of curcumin. Food Anal Methods 2012;5:881-9.

16. Nguyen TX, Huang L, Liu L, Abdalla AME, Gauthier M, Yang G. Chitosan-coated nano-liposomes for the oral delivery of berberine hydrochloride. J Mater Chem B 2014;2:7149-59.

17. Nguyen TX. Isolation of Acetobacter xylinum from kombucha and application of cellulose material produced by bacteria from some culture media for drug carrier. Int J Sci Res 2019;8:1044-9. 